\title{
Introducing Women's Health Reports
}

Susan Kornstein, Editor-in-Chief, and Robert Downs, Deputy Editor

We are pleased to announce the launch of a new online open access journal, Women's Health Reports. Women's Health Reports is a companion journal to Journal of Women's Health and allows for an expansion of the literature into new territories that our flagship journal cannot accommodate due to space constraints imposed by the print format model. Women's Health Reports will provide a home for clinical papers, translational research, and health promotion and wellness articles covering a broad range of topics. Clinical case reports, basic research papers, and other articles that are regional in scope or of interest to specialized groups of readers will be a better fit for Women's Health Reports.

Readers will appreciate this new publication being open access, meaning that no subscription is required to access and read the content. For authors, publishing under a creative commons license allows for them to maintain ownership of their copyright. This model allows for a win-win on both sides and fosters a spirit of openness and collaboration. This spirit is important for driving research in our field forward as we aim to support advances in healthcare for women around the world.

Virginia Commonwealth University School of Medicine, Richmond, Virginia.

(C) Susan Kornstein and Robert Downs 2020; Published by Mary Ann Liebert, Inc. This Open Access article is distributed under the terms of the Creative Commons License (http://creativecommons.org/ licenses/by/4.0), which permits unrestricted use, distribution, and reproduction in any medium, provided the original work is properly cited. 